\title{
BEHAVIORAL AND LIFE-HISTORICAL RESPONSES OF LARVAL AMERICAN TOADS TO AN ODONATE PREDATOR $^{1}$
}

\author{
David K. SKelly AND EARL E. WeRner \\ Department of Biology, University of Michigan, Ann Arbor, Michigan 48109 USA
}

\begin{abstract}
This study examines the responses of larval American toads (Bufo americanus) to the non-lethal presence of an odonate predator (Anax junius). We performed a laboratory experiment where toad larvae were raised at four food rations crossed with the non-lethal presence (i.e., constrained Anax) and absence of the predator. Tadpoles facultatively responded by metamorphosing at smaller sizes in the presence of the predator and at lower food rations. Tadpoles also responded behaviorally to the presence of predators by reducing activity and altering spatial distribution. These latter reactions appeared to contribute to reduced growth rates in the presence of the predator at a given food level. We attempted to separate the effect of the predator on size at metamorphosis into components due to the effect on growth and to more direct effects of the predator, by comparing size at metamorphosis for individuals growing at the same rate in the presence and absence of the predator (i.e., at different food levels). Our data suggest that the metamorphic response may be mediated primarily through the behavioral effects on growth, which then affect size at metamorphosis. These results are consistent with theories of amphibian metamorphosis that predict that size at metamorphosis should depend on the relation between growth opportunities and risk of mortality in the larval and adult habitats. We discuss the importance of non-lethal effects of predators on prey performance, species interactions, and the evolution of prey defenses.
\end{abstract}

Key words: amphibian; Anax; antipredator response; behavior; Bufo; life history; metamorphosis; odonate; predation; tadpole.

\section{INTRODUCTION}

It has recently become apparent that many prey respond facultatively to the presence of their predators. The reported responses have typically been of two sorts, behavioral (e.g., Peckarsky 1980, Sih 1982, Werner et al. 1983, Dill and Fraser 1984, Schmitt and Holbrook 1985, Holomuzki 1986, Morin 1986, Werner and Hall 1988) and morphological (e.g., Grant and Bayly 1981, Krueger and Dodson 1981, Hebert and Grewe 1985, Kuhlman and Heckmann 1985, Lively 1986, Stemberger and Gilbert 1987). In some cases investigators have attempted to measure the costs involved in the alteration of behavior or morphology in order to determine if trade-offs exist and to test a growing body of theory that predicts the appropriate response, given specified costs and benefits (Gilliam and Fraser 1987, Brown 1988). It is now clear that such facultative responses are widespread among different taxa, and often represent an adaptive response to variation in space and time of the presence of mortality risk imposed by predators (see review by Sih [1987]).

Life history theoreticians have also explored the effects of predators on characteristics such as size at maturity or reproductive effort (e.g., Gadgil and Bossert

\footnotetext{
${ }^{1}$ Manuscript received 23 October 1989; revised 9 February 1990; accepted 19 February 1990.
}

1970, Lynch 1980). A number of studies present evidence that the mortality imposed by predators has had an effect on the evolution of life history attributes (see review by Lynch [1980]). However, it has rarely been shown that prey respond in a facultative way to the presence of predators by altering life history characters (for exceptions see Minchella and Loverde 1981, Dodson and Havel 1988, Van Buskirk 1988, Wilbur and Fauth 1990). If such plasticity exists, it provides an important opportunity to test the predictions of life history models in ecological time without recourse to the usual comparative evolutionary studies.

In this study we explore the non-lethal effects of the presence of a predator, larvae of the odonate Anax junius, on life history and behavioral characteristics of the American toad, Bufo americanus. Size at metamorphosis is a critical life history attribute of amphibians (e.g., Berven and Gill 1983, Smith 1987), and has long been known to be a phenotypically plastic character that changes with resource levels or growth rates in the larval stage (Wilbur and Collins 1973). We experimentally demonstrate that size at metamorphosis also changes in the non-lethal presence of Anax (see also Van Buskirk 1988, Wilbur and Fauth 1990). We further examine this response across a gradient of resource levels (growth rates), and discuss possible mechanisms leading to the changes in size at metamorphosis. Some of these possible mechanisms involve 


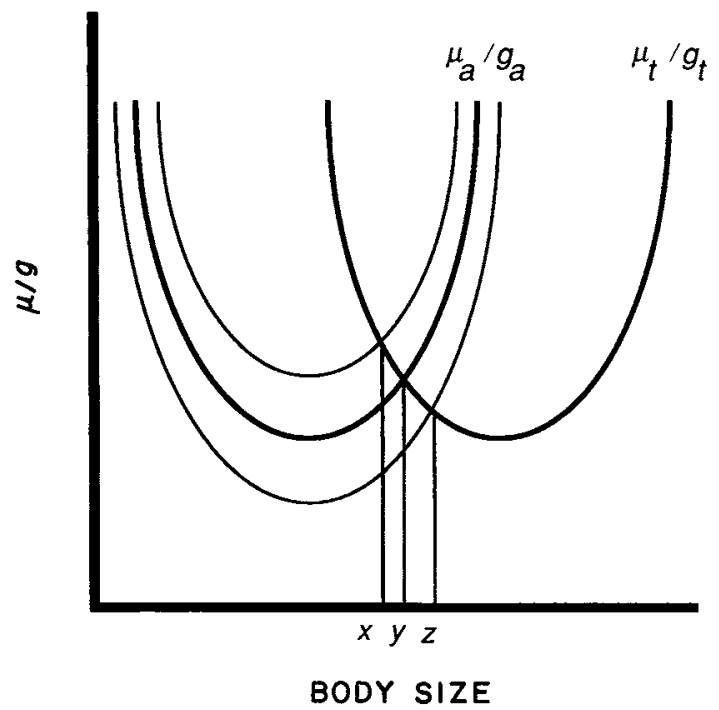

FIG. 1. Hypothetical $\mu / g$ curves as a function of body size for aquatic $\left(\mu_{a} / g_{a}\right)$ and terrestrial $\left(\mu_{t} / g_{t}\right)$ phases of the toad life history. Metamorphosis is predicted to occur at the intersection of the two heavy-lined curves (at $y$ ), so that individuals always minimize $\mu / g$. Factors that degrade the quality of the larval environment should increase $\mu_{a} / g_{a}$ (upper thin-lined curve) and lead to reduced metamorphic size ( $y$ to $x$ ). Increases in the quality of larval habitat should decrease $\mu_{a} / g_{a}$ (lower thin-lined curve) and thereby increase metamorphic size ( $y$ to $z$ ). $\mu=$ size-specific mortality rate; $g=$ size-specific growth rate.

behavioral responses to the presence of Anax, allowing us to relate life history and behavioral responses to each other, and to speculate on their joint consequences to larval toads.

Larvae of American toads occur in a wide range of habitat types from small ephemeral pools to the margins of permanent lakes (Beiswinger 1975, Collins and Wilbur 1979). Larval Bufo co-occur with Anax primarily in fishless ponds of sufficient duration to allow completion of the odonate's larval stage (Brockelman 1969, Formanowicz and Brodie 1982, Van Buskirk 1988 , E. E. Werner, S. A. Cortwright and D. K. Skelly, personal observation). Anax larvae are large (reaching $60 \mathrm{~mm}$ body length) sit-and-wait predators that use a protrusible labium to capture prey across a wide range of invertebrate and vertebrate taxa (Caldwell et al. 1980, Brodie and Formanowicz 1983). Anax is a voracious predator on larval anurans, and appears to be an important predator on Bufo where they co-occur; Brockelman (1969) reported that mortality rates of larval $B u f o$ caged in a natural pond were directly correlated with the density of larval odonates, including Anax. Though some $B$ fo tadpoles are unpalatable to some predator types (Brodie et al. 1978, Kruse and Stone 1984), virtually all Anax brought into the laboratory attacked $B u f o$, and two-thirds of the Anax consumed all individual tadpoles completely (D. K. Skelly and E. E. Werner, personal observation).
THE HYPOTHESIS

Size at metamorphosis in amphibians should reflect the balance of growth potentials and mortality risks experienced in the aquatic and terrestrial stages (Wilbur and Collins 1973, Werner 1986, 1988). Gilliam (1982) showed that when vital rates are size dependent and time invariant, pre-reproductive individuals foraging under predation risk maximize fitness $(r)$ by minimizing the ratio of size-specific mortality $(\mu)$ and growth (g) rates. Thus, the optimal size to shift habitats during the ontogeny is when the quantity $\mu / g$ in the current habitat first exceeds $\mu / g$ in the prospective habitat. Plausible $\mu / g$ curves for the aquatic (larval) and terrestrial (adult) life history stages of an amphibian are presented in Fig. 1 (see Werner [1986] and references cited therein for justification of the shapes of the curves). Addition of a predator to the larval habitat would increase mortality in the aquatic habitat $\left(\mu_{a}\right)$ and thereby elevate the aquatic $\mu / g$ curve, predicting a decrease in metamorphic size (Fig. 1). Similarly, an increase in larval resources would increase larval growth rate $g_{a}$, lowering the $\mu_{a} / g_{a}$ curve and predicting an increase in metamorphic size. In general, if a larva can in some fashion estimate $\mu$ and $g$ and facultatively respond, factors that increase the quality of the larval environment, either by increasing growth rate or decreasing mortality rate, should lead to a larger size at metamorphosis. Conversely, factors decreasing the quality of the larval environment should lead to a decrease in size at metamorphosis.

Perception of predation risk may also induce behavioral responses, such as changes in activity level or habitat use, that reduce $g_{a}$ as well (e.g., Werner et al. 1983). In this case any reduction in metamorphic size could be due to the combination of a response directly to the presence of the predator (perception of increased $\mu_{a}$ ) and a response to the behaviorally mediated reduction in growth rate (perception of decreased $g_{a}$ ). In order to isolate the "direct" effect of the predator it is necessary to compare larvae at identical growth rates in the presence and absence of the predator. We employed a series of food rations crossed with the presence and absence of predators in an attempt to isolate this "direct" effect. The relationship between food level (growth rate) and size at metamorphosis has been demonstrated many times (e.g., Wilbur 1977, Travis 1984, Alford and Harris 1988); our interest in manipulating food concerned possible interactions with the effects of the presence of predators.

Duration of the aquatic stage is another life history attribute of amphibians that has often been examined in relation to metamorphic size (e.g., Wilbur 1984). The $\mu / g$ model makes no simple prediction about changes in larval period; larvae experiencing an increase in predation risk are expected to reduce metamorphic size (Fig. 1), but larval period may be shorter, the same, or longer, depending on the relative growth 
rates in the safer and more predator-rich environments. For instance, if behavioral response to increased mortality risk from predators results in a greatly decreased growth rate, it may actually take longer to reach the smaller metamorphic size predicted by the $\mu / g$ model. However, if larvae experience similar growth rates in both safer and more dangerous environments, the decrease in larval size predicted in the presence of the predator necessarily must be associated with a shorter larval period.

\section{Methods}

The experimental design was a $2 \times 4$ randomized complete block design with treatments being the presence (P) or absence (NP) of the predator (Anax) crossed with four food levels (I-IV) replicated three times in separate blocks (A, B, and C). Twenty four experimental units $(14 \times 25 \times 11 \mathrm{~cm}$ plastic containers each filled with $2.4 \mathrm{~L}$ of water) were established in three blocks of eight containers each on a single laboratory bench. Within each block, treatments were assigned at random to a location within the $2 \times 4$ grid. All containers were fitted with a cylindrical predator cage $(7.5 \times 2.8 \mathrm{~cm})$ constructed of aluminum wire and plastic mesh covered with a sleeve of fiberglass window screening. This assembly was suspended from a dowel in one end of the container. Cages were placed in the containers on day 3 of the experiment. A single fluorescent lamp suspended above the containers provided a 14:10 light : dark cycle. Temperature was $20.4 \pm 0.4^{\circ} \mathrm{C}$ (mean \pm $1 \mathrm{SE}, n=42$ ) and ranged from 15.5 to $26.0^{\circ}$ over a period of the experiment. At no point in time did measured temperatures in the containers differ by $>0.6^{\circ} \mathrm{C}$.

Recently hatched $B$ ufo larvae were collected on 21 May 1988 from a marshy habitat adjacent to Dreadful Hollow (Collins and Wilbur 1979) on the Edwin S. George Reserve near Pinckney, Livingston County, Michigan. Larvae were collected from a single aggregation of similar-sized individuals probably representing a single clutch. Two hundred and forty larvae were selected by eye to be uniform in size, and individuals were haphazardly assigned to an experimental container at a density of 10 individuals per container. Size of the larvae (snout-vent length, mean \pm 1 SD $=$ $0.36 \pm 0.02 \mathrm{~mm} ; n=20$ ) and knowledge of chorusing dates of toads in this habitat suggested that the tadpoles had hatched $\approx 4$ or $5 \mathrm{~d}$ prior to initiation of the experiment. Three tadpoles that died before day 9 were immediately replaced with comparably sized individuals; we did not replace individuals that died subsequently.

Late-instar Anax were collected periodically from a local lake, and were fed either Pseudacris spp. or Bufo tadpoles prior to being placed in P-treatment cages (each Anax was fed the same type of tadpole on a given date). Since Anax were fed prior to introduction into the containers we cannot and do not attempt to make any distinction between the effect of the presence of Anax itself, and the effect of the presence of alarm substances associated with predation on tadpoles (sensu Hews 1988; see also Petranka 1989). Anax were placed in P-treatment cages on day 3 of the experiment and were replaced $\approx$ every $3 \mathrm{~d}$. Of 122 Anax rotated through the experiment (some individuals were used more than once) only 7 died before being removed from the cage. During one 24-h period (on days 23 and 24) the fiberglass screen sleeves were removed from the predator cages in the three highest food treatments in order to reduce surface area for bacterial growth (tadpoles were too large to fit through the mesh of the cages at these food levels). However, sleeves were immediately replaced when it was discovered that $A$ nax could kill the tadpoles through the mesh (see Results: Survivorship).

Size-specific food rations were modeled after those of Alford and Harris (1988), and the four levels (I through IV) were $1 / 20,1.66 / 20,2.33 / 20$, and $3 / 20$ of tadpole mass per day. Food levels I and IV correspond to low - and high-food treatments of Alford and Harris (1988). Tadpole mass was estimated by measuring tadpole volume (density measured at several sizes was indistinguishable from $1.00 \mathrm{~g} / \mathrm{mL}, \mathrm{D}$. K. Skelly and E. E. Werner, personal observation). Estimating mass from volume allowed rapid processing of animals, minimizing disturbance- and handling-induced mortality. Food consisted of a 3:1 mixture of Purina Rabbit Chow to TetraMin Fish Flakes (Alford and Harris 1988), finely ground with a mortar and pestle. Rations were weighed to the nearest milligram.

Tadpoles across all treatments were initially given $0.5 \mathrm{mg}$ of food per tadpole per day for days 0 and 1 . Food treatments were established on day 2 based on average tadpole mass $(20 \mathrm{mg})$ calculated from a sample of tadpoles collected simultaneously with the experimental animals. A subsample of tadpoles from across treatments was used to obtain a mass estimate $(26 \mathrm{mg})$ on day 8 to generate size-specific rations. Mass estimates from day 14 on were made separately for each food treatment by measuring the total volume of tadpoles in each of the containers (both $P$ and NP) at a food level, and determining the mean volume per tadpole. Thus, all containers within a food level received the same ration (scaled to the number of individuals present) regardless of predator treatment. Feeding intervals were initially $6 \mathrm{~d}$, but were reduced to $3 \mathrm{~d}$ on day 20 and finally to $1 \mathrm{~d}$ on day 25 to counteract fouling of the water at higher food levels. Estimates of tadpole mass were made on days $14,20,26,32$, and 44. Well water (aged at least $8 \mathrm{~h}$ prior to introduction) in experimental containers was changed on days $8,14,20$, $23,24,26,29,30,32,38,44,50,52,54$, and 58 of the experiment.

The effects of treatments on activity and spatial dis- 
TABLE 1. Responses of larval Bufo americana to four different food levels in the presence (P) or absence (NP) of a caged dragonfly (Anax) predator. $n=$ the number of survivors (i.e., metamorphs) from that container.

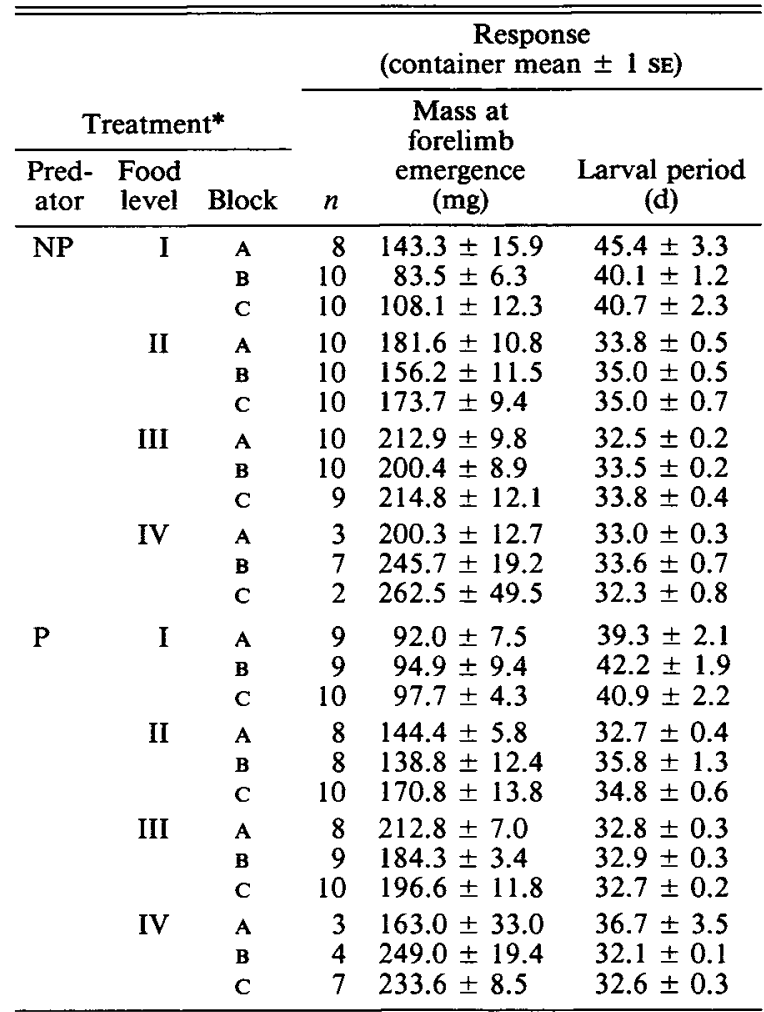

${ }^{*} \mathrm{I}=$ lowest, IV $=$ highest. Blocks and other aspects of experimental design are described in Methods.

tribution of tadpoles were quantified during the experiment. Activity was measured by counting the number of tadpoles in a container swimming at a given point in time. Spatial distribution was measured by counting the number of tadpoles in the half of the container opposite the predator cage. Counts were converted to percentages for purposes of comparison. Distribution was measured from days 5 through 20 . Tadpole activity was measured from days 15 through 20 . Distribution measurements were made on 32 occasions (range: 0 to 3 times daily) and activity measurements on 16 occasions (range: 1 to 3 times daily). Measurements made beyond day 20 were not included in analyses because tadpoles noticeably altered their behavior in the presence of the observer later in their ontogeny.

Metamorphosis was defined as the point when at least one forelimb had emerged (Gosner Stage 42, Gosner 1960). Forelimb emergence represents an unambiguous mark of metamorphic climax among anurans (e.g., Wilbur 1977, Smith 1983, Alford and Harris 1988), and it is the stage at which Bufo ceases feeding until metamorphosis is completed (Beiswinger 1972). In addition, mass at forelimb emergence is highly cor- related $(r=0.90)$ with mass at tail resorption in this species (D. K. Skelly and E. E. Werner, personal $o b$ servation). Containers were checked twice daily during the period when tadpoles metamorphosed, and individuals with erupted forelimbs were immediately removed and weighed to the nearest milligram.

Except where noted, container means were used as response variables in all statistical analyses. Mass at forelimb emergence and larval period were log-transformed to homogenize variances among replicate means. In both cases Pearson correlation coefficients indicated that the log transformation greatly reduced correlation between treatment means and standard deviations calculated across blocks. Activity and distribution (reported as proportions) were angularly transformed for statistical analyses.

\section{RESULTS}

\section{Survivorship}

Overall survivorship until forelimb emergence was $80.8 \%$. The majority of deaths occurred at the highest food level (IV), apparently due to fouling of the water (Table 1). Eight tadpoles in five different containers were killed by Anax through the cage mesh during the 24-h period when the fiberglass screen sleeves were removed in an effort to reduce surface area for bacterial growth.

\section{Metamorphic responses}

Tadpoles in the presence of Anax metamorphosed at significantly smaller sizes, as did those receiving

TABLE 2. Results from three-way ANOVAs without replication of treatment effects on log-transformed values of two response variables.

\begin{tabular}{lrrrr}
\hline \hline a. Mass at forelimb emergence (mg) & & $\begin{array}{c}\text { (Model } \\
\text { Source of variation }\end{array}$ \\
& df & $\begin{array}{c}\text { Sum of } \\
\text { squares }\end{array}$ & \multicolumn{1}{c}{$F$} & $\begin{array}{r}\left.R^{2}=0.98\right) \\
P\end{array}$ \\
\hline Predator treatment & 1 & 0.0124 & 6.33 & .0455 \\
Food treatment & 3 & 0.4357 & 73.81 & $<.0001$ \\
Block & 2 & 0.0064 & 1.65 & .2693 \\
Predator $\times$ Food & 3 & 0.0006 & 0.16 & .9186 \\
Predator $\times$ Block & 2 & 0.0088 & 2.25 & .1866 \\
Food $\times$ Block & 6 & 0.0403 & 3.41 & .0803 \\
Error & 6 & 0.0118 & & \\
$\quad$ Total & 23 & 0.5166 & &
\end{tabular}

b. Larval Period (days)

\begin{tabular}{lrcrc} 
Source of variation & df & $\begin{array}{c}\text { Sum of } \\
\text { squares }\end{array}$ & \multicolumn{1}{c}{$F$} & $\begin{array}{c}\text { (Model } \\
\left.R^{2}=0.94\right)\end{array}$ \\
\hline Predator treatment & 1 & 0.0001 & 0.02 & .9002 \\
Food treatment & 3 & 0.0320 & 30.53 & .0005 \\
Block & 2 & 0.0001 & 0.09 & .9168 \\
Predator $\times$ Food & 3 & 0.0002 & 0.24 & .8681 \\
Predator $\times$ Block & 2 & 0.0001 & 0.02 & .9786 \\
Food $\times$ Block & 6 & 0.0017 & 0.83 & .5881 \\
Error & 6 & 0.0021 & & \\
$\quad$ Total & 23 & 0.0362 & & \\
\hline
\end{tabular}


TABLE 3. Results from 3-way ANOVA without replication of treatment effects on arcsine-transformed tadpole distribution measurements over days $5-20$ (model $\left.R^{2}=0.82\right)$.*

\begin{tabular}{lrrrc}
\hline \hline Source of variation & df & $\begin{array}{r}\text { Sum of } \\
\text { squares }\end{array}$ & \multicolumn{1}{c}{$F$} & $P$ \\
\hline Predator treatment & 1 & 417.83 & 18.39 & .0052 \\
Food treatment & 3 & 14.26 & 0.21 & .8864 \\
Block & 2 & 84.25 & 1.85 & .2360 \\
Predator $\times$ Food & 3 & 20.78 & 0.30 & .8213 \\
Predator $\times$ Block & 2 & 20.41 & 0.45 & .6579 \\
Food $\times$ Block & 6 & 69.86 & 0.51 & .7820 \\
Error & 6 & 136.30 & & \\
$\quad$ Total & 23 & 763.69 & & \\
\hline
\end{tabular}

* Spatial distribution is measured as $\%$ of tadpoles in the half of the container opposite the predator cage.

lower food rations (Table 2a). There was no interaction between predator and food treatments. Overall, presence of Anax resulted in a $9.1 \%$ decrease in individual mass at forelimb emergence, while food-level I tadpoles were $54.2 \%$ smaller than level IV tadpoles when they metamorphosed. Tadpoles in block A of food level IV actually metamorphosed smaller than their counterparts in food level III, contributing to the near significance of the food $\times$ block interaction (Table 2a). Death of the majority of the tadpoles in both of the food-level IV containers in block A may have led to this pattern (Table 1).

Presence of Anax did not affect larval period, but food level had a highly significant effect (Table $2 b$ ). Tadpoles from food-level I had $23.2 \%$ longer larval periods than tadpoles in the other three food levels (see Table 1).

\section{Behavioral responses}

Spatial distribution of tadpoles was significantly affected by predators (Table 3). During days 5 through 20 an average of $70.2 \%$ of the tadpoles were on the opposite side of the container from the predator cage in the presence of Anax compared to $56.2 \%$ in its absence. There was no evidence of any relationship between food level and tadpole distribution. However, distributional patterns exhibited a definite temporal trend that was apparently related to the feeding regime (Fig. 2). During the period when we observed tadpole distributions, there were two consecutive 6-d food rations presented (on days 8 and 14). In both instances food addition was associated with an increase in use of the side of the container opposite the predator cage by tadpoles with Anax. This effect gradually diminished over time, and by the fourth day tadpoles were distributed similarly in both $\mathrm{P}$ and NP treatments.

Tadpole activity was decreased $41 \%$ in the presence of Anax compared to when Anax was absent (mean \% active: $17.8 \%$ vs. $30.1 \%$ ) from day 15 through 20 (Table $3)$. Food effects on activity were not significant $(P=$ .1122 , Table 4 ), but there was a suggestion that tadpoles

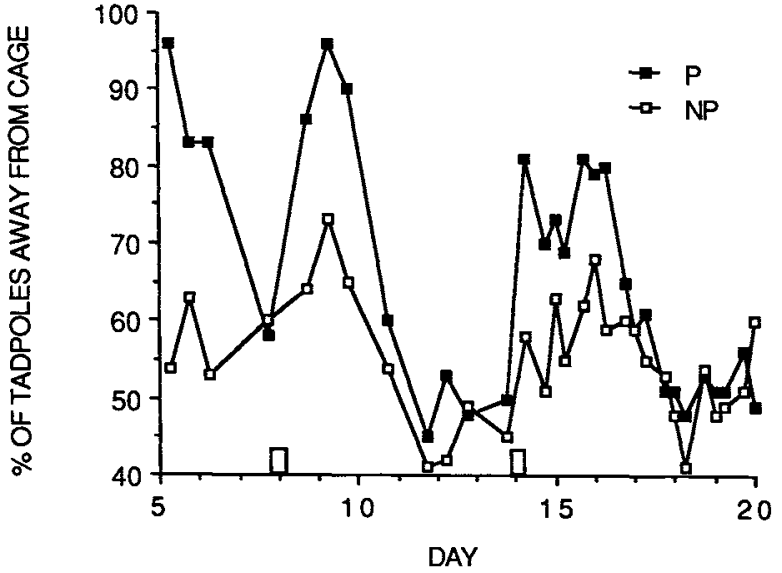

Fig. 2. Distribution of tadpoles within containers with caged predator present (P) and absent (NP) over days 5-20. Presentation of 6-d rations is indicated by hollow bars along the $x$ axis at days 8 and 14. Each point represents the mean of all 12 containers within that predator treatment at that observation time. Standard error bars are not included for clarity of presentation.

were less active at the lowest food level (I) than at the other three (Fig. 3).

Correlations between tadpole activity and growth rate were explored by relating activity over days $15-$ 20 to mean daily growth rate over days $14-20$. The model for this analysis should use growth rate as response, activity as covariate, and food and predator treatments as class variables. However, predator treatment had a strong effect on activity (the covariate), and as a result the effect of predator treatment on growth and the interaction between predator and food treatments on growth would be underestimated (Neter et al. 1985). In order to avoid this problem, analyses of covariance were performed separately on $P$ and NP treatments to examine the effects of activity on growth rate. $\mathrm{P}$ tadpoles that were more active grew faster, as did those at higher food levels (Table 5a, Fig. 4a). In contrast, NP tadpoles grew faster at higher food levels

TABLE 4. Results from three-way ANOVAs without replication of treatment effects on arcsine-transformed tadpole activity measurements over days $15-20\left(\right.$ model $\left.R^{2}=0.82\right)$.*

\begin{tabular}{lrrcc}
\hline Source of variation & df & $\begin{array}{r}\text { Sum of } \\
\text { squares }\end{array}$ & $F$ & $P$ \\
\hline Predator treatment & 1 & 411.01 & 9.77 & .0205 \\
Food treatment & 3 & 388.20 & 3.07 & .1122 \\
Block & 2 & 125.29 & 1.49 & .2986 \\
Predator $\times$ Food & 3 & 28.43 & 0.23 & .8756 \\
Predator $\times$ Block & 2 & 37.33 & 0.44 & .6612 \\
Food $\times$ Block & 6 & 194.69 & 0.77 & .6199 \\
Error & 6 & 252.53 & & \\
$\quad$ Total & 23 & 1437.50 & & \\
\hline
\end{tabular}

* Tadpole activity was measured as the $\%$ of tadpoles in a container that were swimming at a given point in time. Number and frequency of these observation times are described in Methods. 


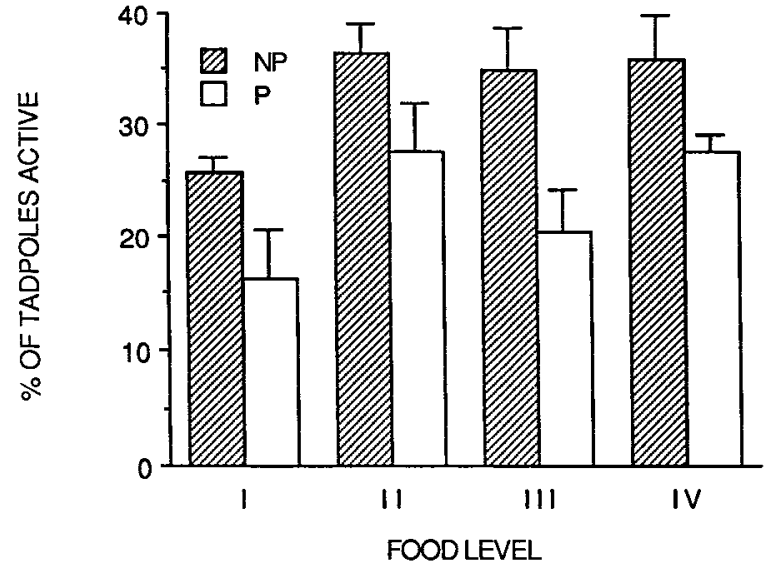

Fig. 3. Mean \% tadpole activity over days 15-20. Each bar represents the mean of three container means, + SE for each food-predator treatment combination. $\mathrm{P}=$ caged Anax predator present; $\mathrm{NP}=$ predator absent.

but activity was not significantly related to growth rate (Table 5b, Fig. 4b).

\section{Discussion}

Our experiment indicated that Bufo alters size at metamorphosis in response to both availability of food and the presence of a predator in the larval environment. Increases in metamorphic size with increases in food level (or decreased density) have been reported in American toads (Brockelman 1969, Wilbur 1977) along with myriad other amphibian species (reviewed in Wilbur 1980, 1984). However, few studies have reported such responses to predators (see Introduction). Recently Van Buskirk (1988) and Wilbur and Fauth (1990) found that larval American toads emerged at smaller sized in artificial ponds (cattle tanks) that contained Anax. Our results confirm this pattern, and permit us to relate the life-historical and behavioral responses to presence of the predator. In so doing we can make inferences about the mechanisms by which $B u f o$ are assessing their environment and responding to predators and food.

Toad tadpoles responded to the presence of Anax by reducing activity $41 \%$, which may reasonably be interpreted as a mechanism to reduce mortality risk ( $A$ nax is primarily a sit-and-wait predator that requires prey movement to elicit a strike; Pritchard 1965, Oakley and Palka 1967). However, this reduction occurred at the expense of a $28 \%$ decrease in growth rate. Moreover, activity and growth were correlated in the $P$ treatment but independent in the NP treatment, suggesting that NP tadpoles may have adjusted activity to maximize growth rate while $P$ tadpoles were forced to trade off activity (risk) and growth rate.

The spatial response of Bufo larvae to Anax would also likely reduce mortality risk (e.g., Holomuzki 1986, Morin 1986, Petranka et al. 1987, Semlitsch 1987,
TABLE 5. Results from ANCOVAs using mean daily growth rate of tadpoles from days $14-20$ as the response variable, tadpole activity from days $15-20$ as covariate, and the four food levels as treatments, for each of the predator treatments separately.*

a. Caged predator present (P tadpoles).

\begin{tabular}{lrrrc}
$\quad \begin{array}{l}\text { Source of } \\
\text { variation }\end{array}$ & df & $\begin{array}{r}\text { Sum of } \\
\text { squares }\end{array}$ & $F$ & $P$ \\
\hline Food treatment & 3 & 45.86 & 8.20 & .0108 \\
Tadpole activity & 1 & 15.95 & 8.56 & .0222 \\
Full model & 4 & 84.42 & 11.30 & .0030 \\
Error & 7 & 13.05 & & \\
$\quad$ Total & 11 & 97.48 & \\
$\quad$ b. Caged predator not present (NP tadpoles). \\
$\quad$ Source of & \multicolumn{4}{c}{ Sum of } \\
$\quad$ variation & df & squares & $F$ & $P$ \\
\hline Food treatment & 3 & 83.59 & 5.06 & .0356 \\
Tadpole activity & 1 & 7.46 & 1.36 & .2822 \\
Full model & 4 & 194.72 & 8.85 & .0070 \\
Error & 7 & 38.51 & & \\
$\quad$ Total & 11 & 233.24 & & \\
\hline
\end{tabular}

* Slopes across food levels were not significantly different from each other $(P=.3022$ for $P$ tadpoles, $P=.1036$ for NP tadpoles).

Hews 1988). However, predator avoidance was strongly related to feeding regime (Fig. 2). Tadpoles avoided Anax to the greatest extent immediately after food was introduced to the containers, and the response gradually diminished over time. If density and/or quality of food declined over the $6 \mathrm{~d}$ between feedings, the temporal pattern of habitat use was consistent with risk balancing behavior. Bufo should exhibit maximal avoidance of $A$ nax when returns initially are equivalent in all areas of the experimental containers. However, as food is depleted in distant regions a tradeoff develops, and tadpoles should increasingly use riskier areas near the predator as the difference in food levels becomes increasingly disparate. We do not know the degree to which this spatial response contributed to the difference in growth rate between predator treatments.

Because toads presumably sacrificed growth rate in behaviorally responding to Anax, the metamorphic response to predator presence could have been mediated entirely through these changes in growth rates (e.g., Wilbur and Collins 1973, Alford and Harris 1988). If, however, $\mathrm{P}$ and NP tadpoles growing at the same rate (e.g., from different food levels) metamorphosed at different sizes, then perception of predation risk must have a more direct effect on metamorphic size. Resolution of this question from our experiment is difficult because growth rates of $P$ and NP tadpoles exhibited different patterns over time (Fig. 5). Analyses of covariance using two different growth-rate estimates to predict metamorphic size yielded conflicting results. If estimates of growth rates over the entire larval period are employed, $\mathrm{P}$ and NP tadpoles growing at the same rate (i.e., comparing $P$ tadpoles at higher food levels 
a. P TADPOLES

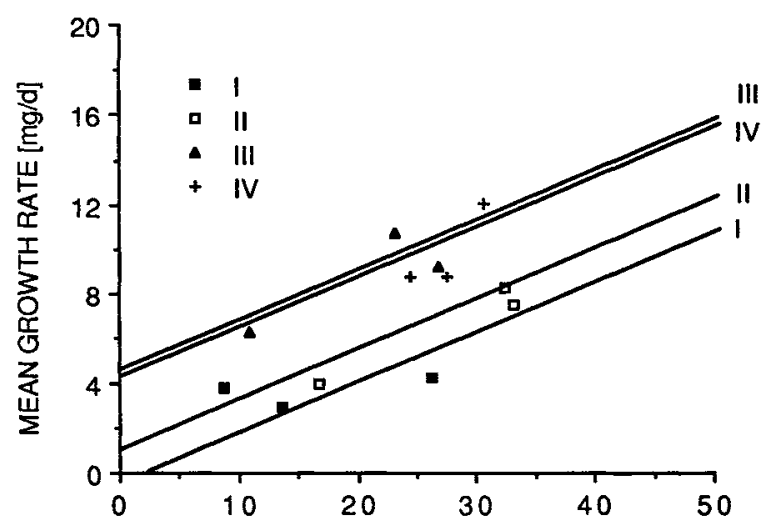

b. NP TADPOLES

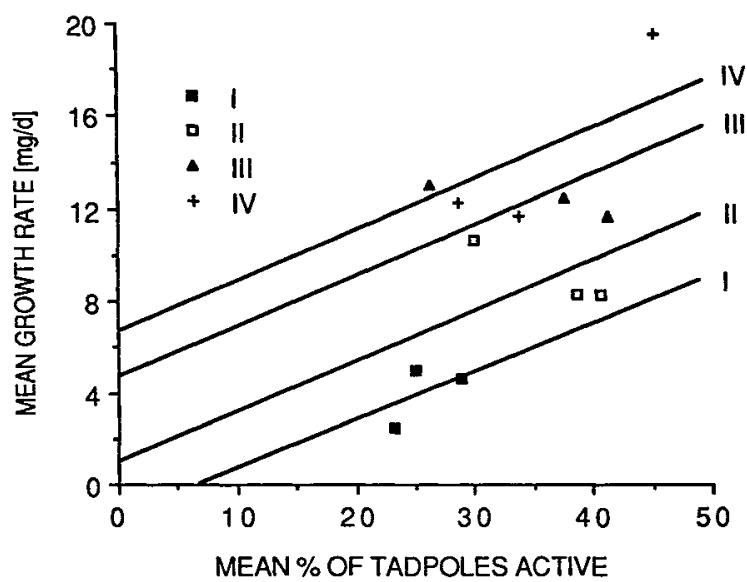

Fig. 4. Mean daily growth rate from days 14-20 plotted as a function of mean tadpole activity ( $\%$ of tadpoles active) from days 15-20. The two predator treatments are plotted separately: $\mathrm{P}=$ caged Anax predator present; $\mathrm{NP}=$ predator absent. Each point represents a single container. Slopes of linear relationships were generated from analysis of covariance (see Table 5). Intercepts were calculated so that the line passes through the point of mean activity and mean growth rate for a given food level.

to NP tadpoles at lower food levels) metamorphosed at the same size (ANCOVA: $F_{1,23}=0.42, P=.5218$ ). However, if growth rates from day 20 until metamorphosis are used instead, it appears that $P$ tadpoles may have metamorphosed at a smaller size when growing at the same rate as NP tadpoles (ANCOVA: $F_{1,23}=$ $3.37, P=.0805$ ). The latter may be the more appropriate estimate, as alterations in growth rate during the larval period can eliminate the effect of prior growth history on metamorphic size (Alford and Harris 1988); but even in this case the magnitude of the metamorphic response attributable directly to predator presence is small. Our results suggest that the metamorphic re- sponse to predators was largely mediated through behavioral effects on growth.

The presence of Anax had no measurable influence on larval period in our experiment. Van Buskirk (1988) and Wilbur and Fauth (1990) reported larval period reductions of 5 and $2 \mathrm{~d}$ respectively in Bufo raised with Anax in small artificial ponds. Their results suggest that under different experimental conditions (e.g., Anax actively preying on larvae) we might have seen a larval period response.

Recent studies suggest that toads respond both behaviorally and life historically to predators in more natural environments in ways similar to those we observed in the laboratory. Ponds are much larger than our experimental containers and may have very different concentrations and gradients of chemicals that tadpoles apparently use in sensing the presence of predators (e.g., Petranka et al. 1987, Hews 1988, Kats et al. 1988). Nevertheless, Petranka (1989) found that American toad larvae in a natural pond responded behaviorally to both food concentration and a conspecific alarm substance associated with predation in a manner similar to our observations. Van Buskirk (1988) and Wilbur and Fauth (1990) also found that toads altered size at metamorphosis in artificial ponds $(\approx 1$ $\mathrm{m}^{3}$ ) that are within the size range of natural habitats.

These responses likely have important consequences beyond the larval stage, and must be considered within the context of the entire life history. Recent studies have demonstrated that an increase in size at metamorphosis in amphibians is correlated with reduced time to maturity (Smith 1987, Semlitsch et al. 1988), increased survival to maturity (Berven and Gill 1983), and increased size at maturity (Berven and Gill 1983,

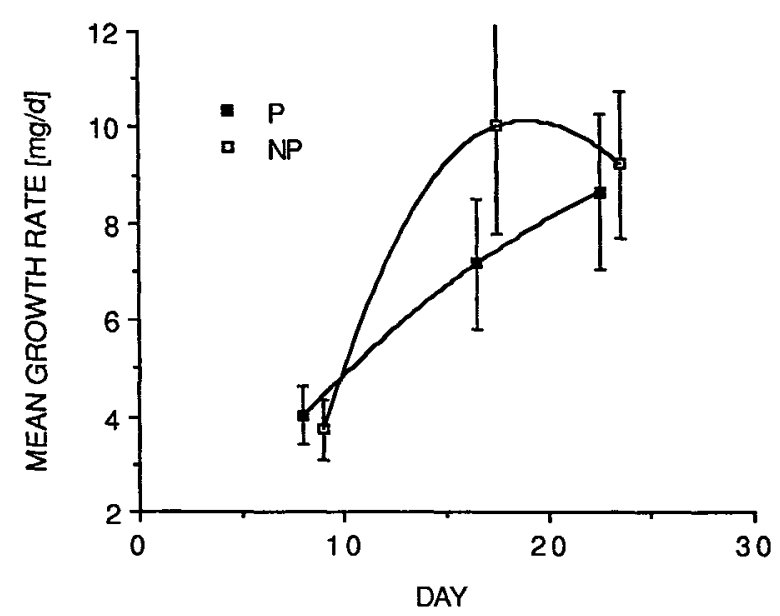

FIG. 5. Daily growth rates for $P$ (predator present) and NP (predator absent) tadpoles over the period prior to the emergence of any metamorphs (means \pm SE). Each point was calculated as the mean growth rate for the four food levels within each predator treatment shown at the midpoint of the 6-d period over which the growth took place (data points are slightly offset for clarity of presentation). 
Smith 1987, Semlitsch et al. 1988), which in turn is correlated with larger clutch size and egg size in females (Tilley 1968, Salthe 1969, Collins 1975, Semlitsch 1985) and increased male breeding success (Wells 1977, 1978, Howard 1980, Berven 1981). Therefore, resources garnered during the larval stage have important implications for adult fitness. Available evidence suggests that ability to garner resources and predation risk are positively associated in tadpoles (e.g., Morin 1981, 1983); our results suggest that larval activity may be a behavioral attribute that contributes to this correlation (see also Woodward 1983). Because metamorphic size is enhanced by rapid growth (e.g., Wilbur and Collins 1973 , this study) and is positively associated with adult fitness (see Introduction, above), to what extent should tadpoles improve larval survivorship (by reducing activity) at the expense of adult survivorship and reproduction? Selection in this situation depends on the shape and strength of the relationships between larval behavior and larval survival, and between metamorphic size and adult reproduction and survival. If decreased activity significantly reduces risk of larval predation and if metamorphic size is only weakly related to adult fitness, then toads should strongly alter activity in response to predator presence. If metamorphic size is strongly related to fitness, then larval activity may be a relatively inflexible trait. That is, when prospects for adult reproduction are small in the absence of rapid larval growth, the risk of predation while a larva becomes relatively less important. In either case, ecological relationships within the adult environment will affect larval behavioral responses.

The results of our experiment emphasize the importance of predator presence in structuring behavioral and life-historical attributes of prey even when the lethal impact of the predator is removed, or is relatively unimportant. Such prey responses potentially affect prey population dynamics (e.g., Abrams 1987) as well as community-level interactions (e.g., Mittelbach and Chesson 1987). Predators may restrict prey to common refuges and thereby locally intensify interspecific competition among prey species (e.g., Mittelbach and Chesson 1987) or cause prey species to spatially segregate, decreasing the intensity of interspecific competition (E. E. Werner and M. A. McPeek, unpublished manuscript). Differential activity or spatial responses to predators by competing prey species could alter both relative competitive ability and susceptibility to predation (E. E. Werner, unpublished manuscript). Tadpoles that do not respond to predators behaviorally may be superior competitors, but at the cost of higher risk of predation.

\section{ACKNOWLEDGMENTS}

We are indebted to several colleagues, including B. R. Anholt, S. A. Cortwright, M. J. Ellis, G. A. Wellborn, and two anonymous reviewers whose comments greatly improved this manuscript. We would also like to thank W. R. Dawson, director, and R. A. Nussbaum, associate director, for access to and use of the facilities of the E. S. George Reserve. This study was supported by NSF grant BSR8796176 to E. E. Werner.

\section{LITERATURE Cited}

Abrams, P. 1987. Indirect interactions between species that share a predator: varieties of indirect effects. Pages 38-54 in W. C. Kerfoot and A. Sih, editors. Predation: direct and indirect impacts on aquatic communities. University of New England Press, Hanover, New Hampshire, USA.

Alford, R. A., and R. N. Harris. 1988. Effects of larval growth on anuran metamorphosis. American Naturalist 131: 91-106.

Beiswinger, R. E. 1972. Aggregate behavior of tadpoles of the American toad, Bufo americanus, in Michigan. Dissertation. University of Michigan, Ann Arbor, Michigan, USA.

-1975. Structure and function in aggregations of tadpoles of the American toad, Bufo americanus. Herpetelogica 31:222-233.

Berven, K. A. 1981. Mate choice in the wood frog Rana sylvatica. Evolution 35:707-722.

Berven, K. A., and D. E. Gill. 1983. Interpreting geographic variation in life-history traits. American Zoologist 23:8597.

Brockelman, W. Y. 1969. An analysis of density effects and predation in Bufo americanus tadpoles. Ecology 50:632644.

Brodie, E. D., Jr., and D. R. Formanowicz, Jr. 1983. Prey size preferences of predators: differential vulnerability of larval anurans. Herpetologica 39:67-75.

Brodie, E. D., Jr., D. R. Formanowicz, Jr., and E. D. Brodie III. 1978. The development of noxiousness of Bufo americanus tadpoles to aquatic insect predators. Herpetologica 34:302-306.

Brown, J. S. 1988. Patch use as an indicator of habitat preference, predation risk, and competition. Behavioral Ecology and Sociobiology 22:37-47.

Caldwell, J. P., J. H. Thorp, and T. O. Jervey. 1980. Predator-prey relationships among larval dragonflies, salamanders, and frogs. Oecologia (Berlin) 46:285-289.

Collins, J. P. 1975. A comparative study of the life history strategies in a community of frogs. Dissertation. University of Michigan, Ann Arbor, Michigan, USA.

Collins, J. P., and H. M. Wilbur. 1979. Breeding habits and habitats of the amphibians of the E. S. George Reserve, Michigan, with notes on the local distribution of fishes. Occasional Papers of the Museum of Zoology, University of Michigan 686:1-34.

Dill, L. M., and A. H. G. Fraser. 1984. Risk of predation and the feeding behavior of juvenile coho salmon (Onchorhynchus kisutch). Behavioral Ecology and Sociobiology 16:65-71.

Dodson, S. I., and J. E. Havel. 1988. Indirect prey effects: some morphological and life history responses of Daphnia pulex exposed to Notonecta undulata. Limnology and Oceanography 33:1274-1285.

Formanowicz, D. R., Jr., and E. D. Brodie, Jr. 1982. Relative palatabilities of members of a larval amphibian community. Copeia 1982:91-97.

Gadgil, M., and W. H. Bossert. 1970. Life historical consequences of natural selection. American Naturalist 104:124.

Gilliam, J. F. 1982. Habitat use and competitive bottlenecks in size-structured fish populations. Dissertation. Michigan State University, Lansing, Michigan, USA.

Gilliam, J. F., and D. F. Fraser. 1987. Habitat selection under predation hazard: test of a model with foraging minnows. Ecology 68:1856-1862. 
Gosner, 1960. A simplified table for staging anuran embryos and larvae with notes on identification. Herpetologica 16: 183-190.

Grant, J. W. G., and I. A. E. Bayly. 1981. Predator induction of crests in morphs of the Daphnia carinata King complex. Limnology and Oceanography 26:201-218.

Hebert, D. N., and P. M. Grewe. 1985. Chaoborus-induced shifts in the morphology of Daphnia ambigua. Limnology and Oceanography 30:1291-1297.

Hews, D. K. 1988. Alarm response in larval western toads, Bufo boreas: release of larval chemicals by a natural predator and its effect on natural capture efficiency. Animal Behaviour 36:125-133.

Holomuzki, J. R. 1986. Predator avoidance and diel patterns of microhabitat use by larval tiger salamanders. Ecology 67:737-748.

Howard, R. D. 1980. Mating behavior and mating success in wood frogs, Rana sylvatica. Animal Behaviour 28:705716.

Kats, L. B., J. W. Petranka, and A. Sih. 1988. Antipredator defenses and the persistence of amphibian larvae with fishes. Ecology 69:1865-1870.

Krueger, D. A., and S. I. Dodson. 1981. Embryological induction and predation ecology in Daphnia pulex. Limnology and Oceanography 26:219-223.

Kruse, K. C., and B. M. Stone. 1984. Largemouth bass (Micropterus salmoides) learn to avoid feeding on toad (Bufo) tadpoles. Animal Behaviour 32:1035-1039.

Kuhlman, H. W., and K. Heckmann. 1985. Interspecific morphogens regulating predator-prey relationships in Protozoa. Science 227:1347-1349.

Lively, C. M. 1986. Canalization versus developmental conversion in a spatially heterogeneous environment. American Naturalist 128:561-572.

Lynch, M. 1980. The evolution of cladoceran life histories. Quarterly Review of Biology 55:23-42.

Minchella, D. T., and P. T. Loverde. 1981. A cost of increased reproductive effort in the snail Biomphalaria glabrata. American Naturalist 118:876-881.

Mittelbach, G. G., and P. L. Chesson. 1987. Indirect effects on fish populations. Pages 315-332. in W. C. Kerfoot and A. Sih, editors. Predation: direct and indirect impacts on aquatic communities. University of New England Press, Hanover, New Hampshire, USA.

Morin, P. J. 1981. Predatory salamanders reverse the outcome of competition among three species of anuran tadpoles. Science 212:1284-1286.

1983. Predation, competition, and the composition of larval anuran guilds. Ecological Monographs 53:119138.

-1986. Interactions between intraspecific competition and predation in an amphibian predator-prey system. Ecology 67:713-720.

Neter, J., W. Wasserman, and M. H. Kutner. 1985. Applied linear statistical models. R. D. Irwin, Homewood, Illinois, USA.

Oakley, B., and J. M. Palka. 1967. Prey capture by dragonfly larvae. American Zoologist 7:727-728.

Peckarsky, B. L. 1980. Predator-prey interactions between stoneflies and mayflies: behavioral observations. Ecology 61:932-943.

Petranka, J. W. 1989. Response of toad tadpoles to conflicting chemical stimuli: predator avoidance versus "optimal" foraging. Herpetologica 45:283-292.

Petranka, J. W., L. B. Kats, and A. Sih. 1987. Predatorprey interactions among fish and larval amphibians: use of chemical cues to detect predatory fish. Animal Behaviour 35:420-425.

Pritchard, G. 1965. Prey capture by dragonfly larvae (Odo- nata; Anisoptera). Canadian Journal of Zoology 43:271289.

Salthe, S. N. 1969. Reproductive modes and the numbers and sizes of ova in the urodeles. American Midland Naturalist 81:467-490.

Schmitt, R. J., and S. J. Holbrook. 1985. Patch selection by juvenile black surfperch (Embiotochidae) under variable risk: interactive influence of food quality and structural complexity. Journal of Experimental Marine Biology and Ecology 85:269-285.

Semlitsch, R. D. 1985. Reproductive strategy of a facultatively paedomorphic salamander Ambystoma talpoideum. Oecologia (Berlin) 65:305-313.

- 1987. Interactions between fish and salamander larvae: costs of predator avoidance or competition? Oecologia (Berlin) 72:481-486.

Semlitsch, R. D., D. E. Scott, and J. H. K. Pechmann. 1988. Time and size at metamorphosis related to adult fitness in Ambystoma talpoideum. Ecology 69:184-192.

Sih, A. 1982. Foraging strategies and the avoidance of predation by an aquatic insect, Notonecta hoffmanni. Ecology 63:786-796.

1987. Predator and prey lifestyles: an evolutionary and ecological overview. Pages 203-224 in W. C. Kerfoot and A. Sih, editors. Predation: direct and indirect impacts on aquatic communities. University of New England Press, Hanover, New Hampshire, USA.

Smith, D. C. 1983. Factors controlling tadpole populations of the chorus frog (Pseudacris triseriata) on Isle Royale, Michigan. Ecology 64:501-510.

- 1987. Adult recruitment in chorus frogs: effects of size and date at metamorphosis. Ecology 68:344-350.

Stemberger, R. S., and J. J. Gilbert. 1987. Defenses of planktonic rotifers against predators. Pages 227-239 in W. C. Kerfoot and A. Sih, editors. Predation: direct and indirect impacts on aquatic communities. University of New England Press, Hanover, New Hampshire, USA.

Tilley, S. G. 1968. Size-fecundity relationships and their evolutionary implications in five desmognathine salamanders. Evolution 22:806-816.

Travis, J. 1984. Anuran size at metamorphosis: experimental test of a model based on interspecific competition. Ecology 65:1155-1160.

Van Buskirk, J. 1988. Interactive effects of dragonfly predation in experimental pond communities. Ecology 69:857867.

Wells, K. D. 1977. Territoriality and mating success in the green frog (Rana clamitans). Ecology 58:750-762.

- 1978. Territoriality in the green frog ( Rana clamitans): vocalizations and agonistic behavior. Animal Behaviour 26:1051-1063.

Werner, E. E. 1986. Amphibian metamorphosis: growth rate, predation risk, and the optimal size at transformation. American Naturalist 128:319-341.

- 1988. Size, scaling, and the evolution of complex life cycles. Pages 60-81 in B. Ebenmann and L. Persson, editors. Size structured populations. Springer-Verlag, Berlin, Germany.

Werner, E. E., J. F. Gilliam, D. J. Hall, and G. G. Mittelbach. 1983. An experimental test of the effects of predation risk on habitat use in fish. Ecology 64:1540-1548.

Werner, E. E., and D. J. Hall. 1988. Ontogenetic habitat shifts in bluegills: the foraging rate-predation risk tradeoff. Ecology 69:1352-1366.

Wilbur, H. M. 1977. Density-dependent aspects of growth and metamorphosis in Bufo americanus. Ecology 58:196200.

1980. Complex life cycles. Annual Review of Ecology and Systematics 11:67-93. 
1984. Complex life cycles and community organization in amphibians. Pages 195-224 in P. W. Price, C. N. Slobodchikoff, and W. S. Gaud, editors. A new ecology: novel approaches to interactive systems. John Wiley \& Sons, New York, New York, USA.

Wilbur, H. M., and J. P. Collins. 1973. Ecological aspects of amphibian metamorphosis. Science 182:1305-1314.
Wilbur, H. M., and J. E. Fauth. 1990. Experimental aquatic food webs: interactions between two predators and two prey. American Naturalist. 135:176-204.

Woodward, B. D. 1983. Predator-prey interactions and breeding-pond use of temporary-pond species in a desert anuran community. Ecology 64:1549-1555. 